\title{
Una experiencia plástica desde mi cotidianidad vinculada a los Diablos Danzantes de Yare
}

Uma experiência plástica da minha cotidianidade ligada aos Diabos Dançantes de Yare A plastic experience from my cotidianity linked to the Dancing Devils of Yare

Carlos JoséMorgado Delgado*

\section{Resumen}

El presente artículo trata sobre una experiencia plástica desde mi cotidianidad vinculada a los Diablos Danzantes de Yare (parte de la fiesta de Corpus Christi declarada Patrimonio Cultural Inmaterial de la Humanidad, por la Unesco, el 6-12-2012,). A partir de mis visiones, creencias y percepciones presentes en mi obra pictórica, hallazgos a partir de experiencia vivida desde los años 1960 hasta el presente. Esta autobiografía estuvo situada en la población de San Francisco de Yare, escenario de grandes dimensiones conectado con los estudios relacionados con el patrimonio inmaterial. Es importante destacar que las complejidades formalizadas y orientadas a la investigación, que aquí abordé, son transformadas en identidades que se expresan desde lo inmaterial con el rito, el mito, el sincretismo, causando euforia y emociones trasmitidas a través del lienzo en el espacio y tiempo del Corpus Christi en la enunciación pictórica como autor. El aporte teórico que se pretendió trazar en esta investigación está orientado hacia la ampliación de una realidad pictórica sociocultural e histórica poco

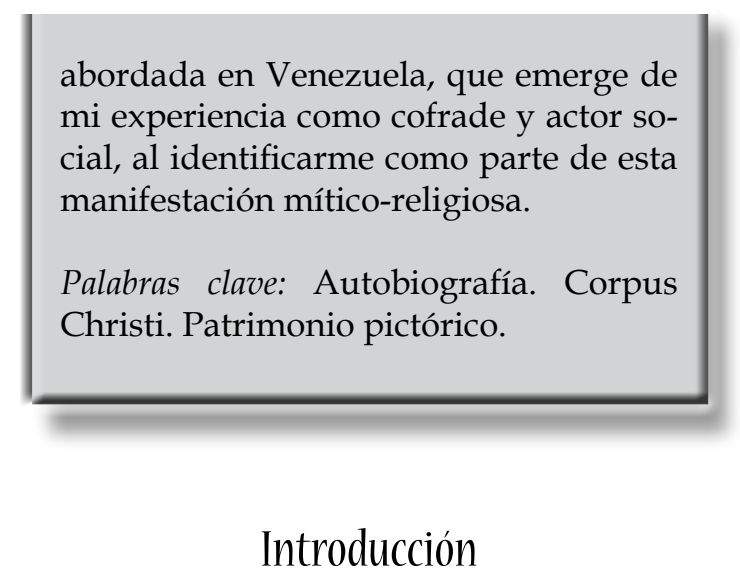

Haciendo un poco de historia he podido darme cuenta que cada ser humano es poseedor de sus propias circunstancias en cuanto a los acontecimientos que van surgiendo desde su entorno y cotidianidad, sintiendo vicisitudes y emociones que re-

Doctor en Patrimonio Cultural por la Universidad
Latinoamericana y del Caribe (ULAC Caracas-Vene-
zuela). Artista Plástico y promotor cultural en con-
servación y salvaguarda de tradiciones de la cultura
material e inmaterial venezolana. E-mail: cmorga-
dodelgado05@gmail.com

Recebido em 02.08.2018 - Aprovado em 14.09.2018 http://dx.doi.org/10.5335/hdtv.19n.1.8908 
corren caminos donde nos encontramos de nuevo, al identificarnos con nosotros mismos con pasajes que no sabíamos que más tarde formarían parte de nuestras memorias e historias de vida, lo cual se convierte en un legado personal que trasmitimos a nuestros hijos, nietos y hermanos, que luego se hace recuento por parte de quienes nunca nos olvidan.

De tal manera que, la teoría que surge del mundo de los hallazgos es la parte más emocionante que viene a conformar la investigación epistemológica construccionista, porque ese producto de nuestras propias maneras de crear, sentir y pensar en las dimensiones, socioculturales e históricas existentes tanto colectivas como individuales, al crear un sistema autobiográfico se convierte en algo muy personal que termina siendo un sello en la estructura al dedicarle un máximo de tiempo a la interacción social de lo inédito y hasta lo novedoso.

Por otra parte, desde mi visión como artista plástico, he podido percibir que al conectarme con otros artistas, de diferentes géneros culturales he podido entender mejor mi contorno social y la comunicación o diálogo al provocar la interpretación de las obras de arte que son exhibidas en los espacios públicos, causando el encuentro con la historia real de nuestra manifestación cultural; en nuestro caso específico los personajes más notables dentro de la manifestación de los Diablos Danzantes de Yare (DDY), en cuanto a la perspectiva visionaria donde la imaginación junto a la creación, se convierte en aspectos que ocasionan maneras diferentes de ver la realidad sociocultural en la cual se desenvuelve, con los actores sociales que se unen, conformando formas colectivas de convivir y expresar cada significado y simbología al romper el paradigma de la memoria colectiva en los espacios abiertos, creando sin ninguna duda el acercamiento a la interacción social que involucra a todo aquel que se aproxima, a veces por curiosidad y otras porque son para todo público.

Después de algunos intentos de ensayo y error, logré alcanzar metas importantes, las cuales quiero evocar aquí a partir de mi historia de vida, ya que representa una ocasión para reflexionar a través de lo que diversos autores como Righetti (2006), señalan que el método autobiográfico tiene sus raíces en el existencialismo, la fenomenología y el psicoanálisis.

Según el autor antes señalado, mediante la memoria descubrimos dentro de uno mismo lo que no sabíamos que poseíamos. Porque con la peculiaridad del narrar, jamás reducible al describir, recorremos de nuevo un camino existencial en el cual nos identificamos. En este método la elección de los recuerdos pertenece a la libre decisión individual, pero para ser verdaderamente "investigación", se hace necesario que el sujeto interprete su propia vivencia a la luz de nexos: "aquello que permite a las cosas ponerse nuevamente en movimiento y encontrar su justa y plausible combinación" (RIGHETTI, 2006, p. 2)

Según revela el pedagogo Duccio que: "Profundizar en el pasado conlleva siempre interpretación y por lo tanto, una forma que puede adoptarse de acuerdo con las preferencias y los estados de ánimo" (1999, p. 3), más allá advierte Righetti, que lo más importante es "el orden evolutivo" del acon- 
tecimiento relatado, la evidencia de un "antes" y de un "después", de un itinerario de crecimiento.

En tal sentido, en el "método autobiográfico", para Duccio:

[...] el pasado corresponde a nuestra identidad; recordarlo con método significa reapropiarse de uno mismo en un trabajo de autoformación. Descubrir las conexiones entre los recuerdos es, de hecho, un aprender, ya que todo recuerdo es un signo que abre la puerta a un acontecimiento y reclama otros signos, otras escenas vitales, en una red de interrelaciones complejas (1999, p. 3).

De tal manera que, se podría decir que el haber logrado darle no sólo como proyección del significado a cada obra, sino también la contribución al plan de salvaguarda tanto local, regional como nacional e incluso internacional, a la manifestación más antigua del continente americano, es mi decidida voluntad de pintar la cofradía, sus expresiones, hechos y acontecimientos, para ser interpretados por todo público.

También tengo que destacar las visiones que como artista plástico amplían mis dimensiones desde ese mundo mágico que me envuelven al crear como es el caso de mis espacios al pintar, lo que permite convertirme en un personaje que viaja de una dimensión a otra al conectarse con la creación, en profunda concentración, para luego regresar casi sin darme cuenta del ahora en mi tiempo y espacio al estar en otros lugares de la inconciencia.

\section{La pintura en los espacios abiertos: un Realismo Social Incluyente}

Se podría decir que para los tiempos de César Rengifo, Armando Reverón, Manuel Cabré, Emilio Boggio, Rafael Monasterios, Tito Salas, Marcos Castillo, Pedro Ángel González, entre otros, ilustres artistas venezolanos, la pintura no fue un simple momento de creación, también tuvo que ser de compartir sus luchas e inquietudes, discusión por las distintas temáticas de la plástica en su tiempo cargadas de problemas sociales y culturales, sobre todo el de los ciudadanos de tercera clase despreciados por una sociedad incomprensible, intolerante, que dio lugar a una nueva tendencia o maneras de expresarse a través del arte pictórico vanguardista de su tiempo, de llegar a conocerse entre sí, de apoyo mutuo y sobre todo, a fortalecer el debate y conceptualización del arte pictórico.

Figura 1 - Cuadro Carlos Morgado. Exposición de artes plásticas: el día jueves de Corpus Christi, 2014, municipio Simón Bolívar en San Francisco de Yare, estado Bolivariano de Miranda, Venezuela.

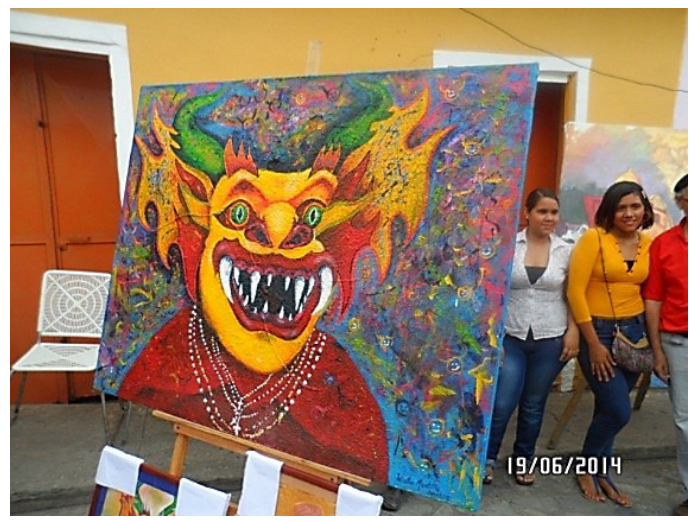

Fuente: acervo del autor 
En nuestro contexto social actual donde la sociedad relacional se expresa en una fuerte labialización de vínculos barriales de vecindad y familiares extensos, así como los gremiales y de participación política, prácticas artísticas, se constituyen en un espacio posible de resistencia como salvaguarda. Desde organizaciones sociales y comunitarias las obras artísticas para la transformación social alejadas de formaciones puramente formales o estéticas devienen esencialmente procesuales y saltan al contexto social con voluntad de promover un beneficio comunitario.

Bang (2013) señala que se trata de una forma de creatividad al servicio de la comunidad trabajando para la conformación de vínculos y espacios de encuentros creativos. Podríamos situar estas prácticas en lo que se ha dado en llamar arte comunitario, con origen en los planteamientos que en los años sesenta integraron dos tendencias claves: en primer lugar la idea que el significado del arte debe encontrarse en el contexto (físico - social) y no en el objeto autónomo, y el nuevo interés por el público y por las formas de implicarlo en las obras de arte (PALACIOS GARRIDO, 2013).

Cabe destacar, por otra parte, que Cesar Rengifo entre 1948-1980 escribe sobre el arte y la cultura nacional expresando la importancia que tiene la cultura para una nación; parte de que en ella se expresa en conjunto la vida activa y creadora de esa nación, tanto en lo material como en lo intelectual y lo moral.

Muchos artistas por lo general trabajaban de manera solitaria, y un tanto egoísta al no permitir contacto alguno con otros virtuosos o público, para no transferir el significado que tiene la cultura popular que tiene lugar a partir de las luchas sociales, para crear la integración de apoyo al proletariado, las manifestaciones reivindicativas, o necesidades primarias, de obreros y desigualdades reclamando justicia, y las manifestaciones culturales populares exigiendo respeto a la dignidad humana, $\mathrm{y}$, por otro lado, guardarse celosamente el conocimiento que imposibilita el acceso a la transmisión y comprensión del arte visual.

La actitud positivista desconoce lo más importante que es la trasmisión de los saberes al pueblo, para crear la condición sociocultural y política para fortalecer tanto las destrezas del aprendizaje como la convicción histórica de nuestra realidad e identidades en lo colectivo y lo individual, por los actores sociales que son los constructores culturales, con sus propias capacidades de creación y razonamiento producto de la experiencia con la comunidad que los reconoce por lo que hacen y realizan, en la importancia que profundiza la armonía y nos integra colectivamente.

Entrevistando a varias personas que se encontraban observando las obras plásticas, ese día jueves del Corpus Christi, entre los cuales estaba el músico e investigador Gustavo Solórzano, después de observar e interpretar, me respondió lo siguiente:

Creo que debes seguir profundizando en el tema, el cual debes aclarar que es a través de tu experiencia, porque eres tú que lo estás haciendo, eres el que lo siente y eres el que lo expresa a través del lienzo, con tus propios colores, los cuales poseen diferentes técnica que se nota en tu 
pincelada plasmada en el lienzo. En cierta forma, has captado las expresiones, con ese sentimiento religioso devocional, emocional que en el quehacer vivo de la expresión cuando están en pleno ritual se manifiesta los individuos, en la celebración del Corpus Christi donde se le observa esa espiritualidad, esa magia presente allí, esa actitud devocional presente allí, a veces de miedo ante el demonio o miedo ante el castigo que puedan recibir por no cumplir la promesa realizada, como esos elementos simbólicos desde el punto de vista religiosos de la creación y creencia que se encuentran representados a través de los colores a través del dibujo, a través de la tela en tu obra.

De allí que Heidegger considera la plástica como:

La corporeización de la verdad del ser en la obra que instaura lugares. $\mathrm{Al}$ considerar el arte y la técnica científica de creación y elaboración del espacio con intenciones diversas y de diversas maneras. ¿Es por tanto la plástica la conquista técnocientifica del espacio? ¿Se ven así conformadas con carácter contemporáneo?, ¿no responden las modernas artes figurativas a este mismo desafío? (2003, p. 28).

Ambas aproximaciones son relevantes para el proceso constructivo del artista como individuo colectivo.

\section{Enmarcados en una misma realidad pictórica}

Hay dos escenarios vivientes el día jueves de Corpus Christi, que demuestran que existen, comparten y se proyectan al mismo tiempo, uno al lado del otro dentro del gran escenario del pueblo de San Francisco de Yare.

Particularmente, considero que el arte depende de quien lo interpreta, tenga y sensibilice para poder sentir de alguna manera los efectos producidos la obra pictórica; digo esto basado en mi teoría que se enmarca en la visión trasmitida por dos enfoques producto de una misma realidad, que consiste en presentar en el mismo lugar de los hechos, lo que proyecta cada uno desde una misma perspectiva. Uno al lado del otro, expresándose al mismo tiempo en su justo espacio real, de caballete, en contenido inmaterial, de manera permanente, histórica, en tiempo y espacio; expresiva, movible, religiosa, pagana, rindiéndole culto al "Santísimo del Altar" en su gran escenario natural del pueblo de San Francisco de Yare.

Y el otro, expresándose bajo el sentimiento del pincel, descansando en su caballete, sereno, proyectándose como plan de salvaguarda, atento a la interpretación en expresión visual. Si algún visitante le observa de inmediato se proyecta en movimiento de diferentes expresiones enmascaradas visualizando su indumentaria de color rojo, al mezclarse, producidos por el arte expresionista e impresionista, con los efectos complementarios que a mi manera de ver, expresan los mismos sentimientos y significados simbólicos subjetivos.

En este sentido, desde mi hacer cultural pictórico, la investigación cualitativa da inicio al surgimiento de estos hechos que, aparte de ser visibles y notorios, son reconocidos tanto por la comunidad pictórica y artesanal al comprender los hechos al relacionarme con los propios manifestantes 
de la Cofradía de los Diablos Danzantes de Yare, al expresar en las entrevistas que yo como pintor con mis obras como me vinculo al patrimonio cultural inmaterial en sus primeros momentos, cuando aún ellos eran desconocidos en gran parte por Venezuela y el mundo.

El arte de la calle con alternativa visual, expresivo, directo, desafiante, que comparte su visión transformadora con todos los participantes; ampliando su conocimiento en la memoria colectiva al establecer sus razones que surgen de las distintas interpretaciones de sus participantes, lo queue incluye a todo aquel que se acerca, bien sea por curiosidad o por querer saber de qué se trata; lo importante es que observar las obras pictóricas en la calle, y tener consciencia de que el compartir una idea con el otro al respecto es conocimiento.

El Corpus Christi de este año 2018 cayó en el mes de mayo, concretamente el jueves 31 , debido a que es una fecha movible dependiendo del último jueves de la Semana Mayor, los nueve jueves a partir del último jueves. Este año realmente la organización de la Cofradía y organizaciones como la Gobernación de Miranda conto con todo el apoyo gubernamental para lo que tiene que ver con un buen desarrollo cultural y religioso. La importancia de esta manifestación es de magnitudes muy elevada por ser una de las culturas de más componentes históricos en nuestra zona de los Valles del Tuy.

Es importante resaltar que este año las plegarias más significativas presentadas por los promeseros estuvieron relacionadas con peticiones hacia la lluvia ya que tenemos una prolongada sequía que nos está ocasio- nando problemas en nuestro aseo diario, la represa de Lagartijo está totalmente seca, al igual que en otros estados de la nación, no existe mayor vocación que el llamado de la manifestación para que podamos tener en cualquier momento el preciado líquido y, también rogar por la paz de Venezuela.

En este contexto ceremonial, Solórzano (2017) señala que en Venezuela el palo de agua $^{1}$ tiene dos significados: uno se refiere al instrumento musical que produce un sonido similar a la lluvia, y otro (el relacionado con el presente tema) referido a una fuerte lluvia, "torrencial aguacero", con truenos, relámpagos, briza fuerte y a veces huracanadas, que se prolonga por cierto tiempo. En el caso de Yare, es realmente interesante señalar que en todas las celebraciones del jueves del Corpus Christi se desata en cualquier momento del día, un tremendo "Palo de Agua", es un hecho que muchos promeseros lo consideran como la respuesta espiritual del Santísimo Sacramento a la petición que le hicieran los promeseros.

Dejando de lado la visión religiosa, pero a su vez de la mano con ella, está el aspecto socio-político que permite la celebración cada año; así la razón por la cual existen cambios y mudanzas significativos a nivel de abordaje cultural de la manifestación se debe entre otros aspectos, al agotamiento del modelo cultural dominante que interpreta monolíticamente el desarrollo cultural como un proceso de crecimiento institucional y programático para la satisfacción "estandarizada" de las necesidades ("carencias") culturales de algún sector vinculado con las perspectivas actuales que reclaman discutir bases culturales de la sociedad. 
Ahora bien, Venezuela para alcanzar otro estilo $\mathrm{u}$ otro modelo de desarrollo enmarcado en el paradigma de una democracia cultural plural, sustantiva, integral y protagónica debe realizar un Plan Nacional de democratización de la Cultura donde los artistas, los creadores, desde los espacios abiertos con sus argumentos a través de la cultura y publicación, pueden encontrar su propio camino, lo que requiere de innovaciones, ya sea desde la ruptura o desde la adaptación.

Políticas de acciones referidas al fortalecimiento de los procesos y las dinámicas culturales propias de las comunidades, auténticos creadores y transformadores de valores culturales en los asuntos que conciernen y afectan a las comunidades con la finalidad de propiciar el papel protagónico de éstas, ayudan a la toma de decisiones, asumida desde la perspectiva política del desarrollo nacional. En tal sentido, el momento político y social que se vive en Venezuela, le exige al sector cultura modelar la gran pieza de creación colectiva superando los modelos anárquicos de desarrollo, con creatividad, conocimiento, innovación, para recomponer las causas de una sociedad fragmentada.

\section{De mis cuadros salieron los Diablos danzando al mundo}

Comencé colocando cuadros en la vía pública del pueblo de San Francisco de Yare, concretamente en la Plaza Bolívar, cada vez que llegada el día jueves del Corpus Christi, impulsado por querer dar a conocer lo que sabía hacer desde muy niño, de querer expresarme a través del lienzo y mostrar mis pinturas reflejando a los Diablos de Yare. Ese inicio motivó a otros artistas de la plástica y escultores a sumarse hasta formar un buen equipo de creadores dentro de los cuales estaba el gran amigo Luis Ramón Camero ( ya desaparecido físicamente) llamado cariñosamente "El pintor de Charallave" (había nacido en dicha población situada en el municipio Cristóbal Rojas), también se sumó Eladio Marcano, el pintor de los "Indios Coromotanos" ${ }^{2}$ de Ocumare del Tuy, y más tarde mi gran amigo de muchas andanzas por este mundo del arte, Enrique Rojas Rosales "El poeta del pincel".

Los hechos en el lugar y acontecimientos en plena discusión con su mística, expresiones y alaridos producidos por la "diablada", en el marco del Corpus Christi, escenificando desde un contexto natural de cielo y tierra que, en la mayoría de las veces, la lluvia cae como cortina majestuosa que abre el escenario para dar inicio a tan significativo espectáculo que enmarca la manifestación mágica y religiosa del pueblo de San Francisco de Yare.

Por lo tanto, la participación de la obra pictórica ha jugado y sigue jugando un papel muy importante desde hace medio siglo, al ser constante en el espacio y tiempo de proyección, con participación de artistas tanto locales como nacionales e internacionales, tributando, con su presencia la manifestación en su reconocida declaratoria como Patrimonio Cultural Inmaterial de la Humanidad (UNESCO, 2012). Las palabras expresadas textualmente por Pablo Azuaje, Capataz de los DDY, en su hogar de la parroquia de San Francisco de Yare, del municipio Simón Bolívar, en el mes de abril de 2016, al ser entrevistado y grabado por mi. 
Figura 2 - El Capataz Pablo Azuaje, acompañado dos promeseros, 2017

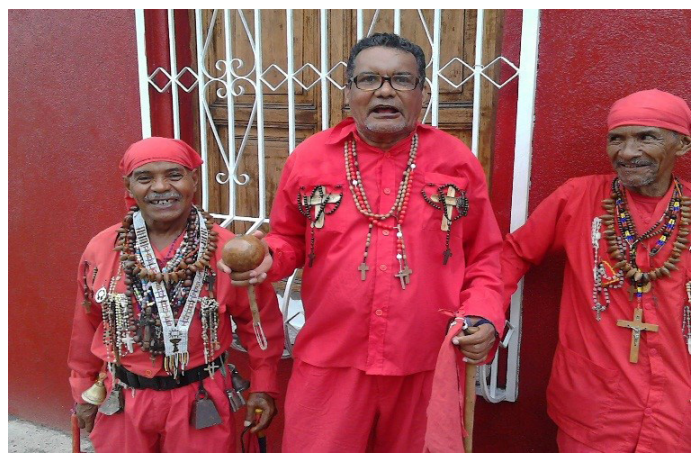

Foto: acervo del autor.

En entrevista el 28-03-2016, le pregunté qué opinaba sobre la pintura que yo realizo de la manifestación DDY, desde hace cincuenta años. Su respuesta me sorprendió enormemente al oírle decir con mucha claridad y emoción:

Nosotros, somos reconocidos como Patrimonio Cultural de la Humanidad gracias al trabajo permanente y constante que tú, Carlos Morgado, como pintor y artista plástico has venido realizando y proyectando, llevando por el mundo tus cuadros a exponerlos, con el objetivo de dar a conocer la manifestación, que son el reflejo de los DDY.

El trabajo del día a día, año tras año, mes tras mes, ha significado que ese trabajo haya traspasado las fronteras venezolanas y al traspasar las fronteras venezolanas llegó a la UNESCO, porque si ustedes no hacen ese trabajo nosotros no fuésemos conocidos en el exterior, porque nosotros lo que hacemos es danzar el día de Corpus Christi aquí en San Francisco de Yare, por pago de promesas, pero ustedes proyectan, ustedes elaboran pinturas, ustedes sacan fotografías, ustedes llevan videos y eso se trasmite al mundo entero y al mundo entero también llegó al oído que allá en San Francisco hay un pueblito pequeño, pero se ha conservado una tradición de doscientos y pico de años gracia a la elaboración de ustedes en su trabajo que se ha mantenido en el transcurso del tiempo de generación en generación y gracias a ese trabajo de ustedes nos ayudó a que nosotros hoy día fuéramos Patrimonio Inmaterial de la Humanidad.

De lo antes dicho, también se refirió a mi hermano Juan Morgado, quien a través de sus máscaras a recorrido el mundo, siendo actualmente reconocido como maestro artesano y Patrimonio Nacional, y quien como promesero y hacedor de máscaras ha participado religiosamente todos los años el día jueves del Corpus Christi, y como artista, expuesto sus máscaras en distintos museos del mundo.

\section{Yare:Magia, costumbrey tradición, unafe incuestionable}

Siempre hay esperanzas y el Santísimo le cumple al promesero, cuando existe fe de corazón todo puede ser posible. En ese virtuosismo contado por los mismos promeseros y personas que nos llegan desde lejos, existen muchas historias. Al preguntar a los que danzan sobre la fe, inician narrando sus anécdotas milagrosas y terminan en llanto por lo vivido. Tal es el caso del Capataz de los Diablos de Yare, Pablo Azuaje, ${ }^{3}$ quien me contó el caso de su hija más pequeña, la cual enfermó de bronconeumonía y casi de 
inmediato se fueron al médico en Caracas, al Hospital de Niños José Manuel de los Río.

Pablo desesperado, rogaba al Santísimo por la salud de la niña y al llegar el doctor les manifestó preocupado que si hubiesen llegado un poco más tarde se les habría muerto, pues convulsionó allí mismo, pero la enfermera, con una velocidad tremenda, le colocó una transfusión de sangre que en el acto le impidió tener un paro del corazón. Estos relatos que se repiten una y otra vez en San Francisco de Yare, vienen a formar parte de nuestra fe religiosa, con la cual se tiene respuesta del altísimo y va creando un compromiso de cada una de las personas con su creencia y anegada manera de sentir y servirle al Santísimo Sacramento, que no es otro más que el Gran Poder de Dios.

Ahora bien, de la manifestación se escuchan muchas anécdotas, contadas por la mayoría de sus promeseros, lo que indica que si existe un poder espiritual que protege a los participantes que, de una $\mathrm{u}$ otra forma, desbordan toda su religiosidad la cual luego se convierte en solución a sus problemas. Tal es el caso del niño Ángel Alberto Millar, que a la edad de 8 años, en 1988, le diagnosticaron leucemia aguda. Este diagnóstico hizo correr desesperadamente a toda su familia, quienes no sabían qué hacer; encontrándose luego en sala intensiva, llegó a perder peso por las quimioterapias recibidas de manera continua. Alguien de la familia le sugirió a la madre que le pidiera al Santísimo Sacramento del Altar por la salud del niño, y que al mejorarse lo llevara a bailar Diablos a San Francisco de Yare.

Al pasar el tiempo, el niño se enteró a través de su madre que el Santísimo lo iba a curar, luego el niño le preguntó a la madre, y ¿cómo es ese Santísimo?, ella le dijo que es un viejito que hace milagros, pero tenía que él debía tener fe y que irían hacia San Francisco de Yare a bailar Diablos como promesa al Santísimo. De acuerdo al relato de su madre, Olivia María Piñate, "un día encuentra al niño en la habitación del hospital realizando un dibujo con la figura de un viejo, lo cual le sorprendió, cuando el niño le dijo mamá así es el Santísimo". Esto causó mucha impresión a su madre, al ver el dibujo que representaba la figura del Santo Patrón de San Francisco de Padua, de Yare.

Esto fue concebido a través de una conversación sostenida con la madre del niño en la cual estuve presente, al ser donante de sangre en el Hospital Pérez Carreño de Caracas, Venezuela, para salvar al niño. De allí que, luego de un tiempo entre exámenes y espera, el niño comenzó a dar síntomas de recuperación de su estado de salud.

\section{Conversando con personalidades de la cofradía y personajes de Yare}

En diálogo sostenido con Alida Díaz de Blanco, quien fuera una de las herederas de la Casa Museo de Simón Bolívar en Yare, más tarde fue adquirida por la gobernación del estado Bolivariano de Miranda, por ser un Patrimonio Nacional y herencia de la familia Díaz, quienes a su vez eran descendientes del Libertador Simón Bolívar. Ella considera que Carlos Morgado es un artista que conocemos desde muchos años, querido por la familia, y que ha llevado bien en alto lo que significa todo el patrimonio con sus cuadros de diablos, de esa tradición que se ha llevado en Yare en toda su historia. 
En realidad me parece una persona muy dedicada, siempre ha estado con su pintura, específicamente de los Diablos Danzantes de Yare, que lo ha llevado a muchos países, que conocen de la trayectoria de su pintura como tal, que en realidad, como todo yo lo conozco a él y a su familia.

[...]

Pregunta: ¿Usted cree que mi obra ha contribuido a proyectar los DDY?

Respuesta: mucho, mucho, claro que sí, ese es el único pintor que en Yare ha promovido todo lo relacionado a los DDY, sus características, ¿qué más puedo decir, de ese muchacho?...muchas cosas, muchas cosas, figúrese que ha llevado sus obras lejos; creo que ha contribuido a lo que fue hace poco esa denominación como Patrimonio Cultural de lo inmaterial de la Humanidad con su obra.

Pregunta: ¿Cuál de sus cuadros le ha gustado mucho más que otros, algún tema específico?

Respuesta: muchos, ya que tenemos varios cuadros de él, en especial dos, que me han gustado mucho, uno es el Diablo Borracho y el otro es donde están muchos integrantes de los diablos en la cual está una persona muy querida para mí, y por eso, bueno guardo muchos recuerdos.

Ahora bien, no me queda más que despedirme de usted y darle las gracias por su testimonio tan importante, el cual ha de servirme para formar parte de mi autobiografía y mi realidad sociocultural histórica y política, la misma a de contribuir para que yo con mi narrativa y testimonios orales, pueda demostrar un elementos más de mi experiencia, vivida durante cinco décadas a través de mis obras artísticas en relación a los DDY.

Testimonios del Director de Cultura Municipal, Francisco Herrera, (indo), el 14 de febrero de 2015, en la Casa de la Cultura Municipal de San Francisco de Yare.

Bueno desde ya le deseo mucha suerte a Carlos Morgado, por tomar una decisión importante para elevar más a nuestro pueblo San Francisco de Yare. actualmente soy el director de cultura municipal, tengo bailando Diablos 20 años en Yare, pagando mi promesa al Santísimo Sacramento del Altar; hablar de Carlos Morgado es hablar de una institución, en lo que es el área de las Bellas Artes, específicamente de pintura, tanto a nivel municipal, Estadal, Nacional, incluso me atrevería a decir que hasta internacionalmente ya que ha llevado sus obras a muchas exposiciones, y en lo que concierne al pueblo cada vez que hay festividades del Patrón y el día jueves del Corpus Christi. Siempre ha estado presente él en conjunto con otros pintores del municipio, se ha apoyado mucho con sus cuadros sobre la manifestación de los Diablos; bueno tiene una gran gama de cuadros sobre la manifestación, mucho antes de que fuera decretado Patrimonio Cultural Inmaterial de la Humanidad, ya Carlos estaba en esas andanzas de llevar mediante sus cuadros la tradición religiosa folclórica que son los DDY [...]. Nada más que el simple hecho de la divulgación, ya eso influye; esos viajes que has hecho llevando estos cuadros de la manifestación obviamente nos han dado a conocer más de lo que ya éramos, porque donde siempre llega un yarence con algo de Yare, ya está demostrando que es un pueblo guerrero, un pueblo de Bolívar, un pueblo del Santísimo Sacramento del altar. Bueno cada vez que se hacen estas exposiciones dentro y fuera del país nos dan a conocer mucho más y obviamente contribuyen a ser conocidos y llegar a ser nombrados como Patrimonio Cultural Inmaterial de la Humanidad. 
En una experiencia vivida con Olivia Piñate, el día miércoles 14 de febrero de 2018, en San Francisco de Yare, expresa lo siguiente:

la obra de Carlos Morgado es importante porque ha servido de difusión a las personas que viajan desde otros espacios y no tienen conocimiento sobre los DDY; su obra contribuye a la formación del conocimiento para los trabajos de investigación tanto de Escuelas, como de Liceos y Universidades, permitiéndoles conocer mejor nuestras raíces históricas.

De lo antes expresado, considero que todo se ajusta a la realidad social de comprender, desde la subjetividad, que no por casualidad mi obra pictórica transitó desde La Casa de Simón Bolívar de La Habana, Cuba, hasta la UNESCO en Francia.

Uno de los componentes más importantes, fue recorrer durante medio siglo con mi obra plástica los distintos escenarios locales, regionales, nacionales e internacionales, haciendo posible su reconocimiento al interpretar sus expresiones y costumbres, los cuales están consagrados en la manifestación, como ningún otro; mi persistencia en el tiempo y en el espacio de San Francisco de Yare será hasta que Dios me de vida y me permita seguir pintando cada suceso, cada expresión, como el primer día, a sus promeseros, rituales, simbolismos, sincretismo y todo lo que ancestralmente producía y produce la manifestación de los DDY. Un día sin darme cuenta de su importancia, creé el Plan de salvaguarda y las condiciones para su Declaratoria universal, como parte del Patrimonio Cultural Inmaterial.
Los espacios abiertos como fuerza emergente epistemológica de resistencia para salvaguardar la identidad de los Diablos de Yare, desde mi perspectiva pictórica han sido de gran importancia por el conjunto de expresiones rituales, mitos y sincretismo encontrados en cada tema que ópticamente así lo devela, donde se podría decir que el espacio urbano también ha evolucionado al tratar de entender, explicar o comprender a través del diálogo, la causa de la interacción social del encuentro que transformó la manera de observar y ver el arte como arte, para tratar de comprender el significado existente en la obra de arte. Desde ese punto de vista, Camnitzer menciona lo siguiente:

El Arte Contextual "Contextual Art" (arte contextual) fue la categoría acuñada por Camnitzer para caracterizar un arte de "resistencia". Esta categoría revela, en línea con su afirmación "la calidad artística no es objetiva sino contextual", la correspondencia que según Camnitzer debe existir entre la obra y su sociedad productora/receptora, y cómo el aparato entero de valoración artística pretende ser cuestionado (1992, p. 71).

Del mismo modo que el espacio público ha hecho posible no solo el reconocimiento de la obra pictórica en el espacio público como arte social en función del ser humano, sino también para que se conozcan las técnicas del arte que socializa el significado decada obra al haber evolucionado junto a la manifestación y poder comparar el antes y el después que sigue interpretándose bajo el discurso conceptual, entre actores sociales que la reconocen y explican, porque existe desde hace mucho tiempo en defensa en el Plan de Salvaguarda del Patrimonio Cultural Inmaterial de los Diablos de Yare. 
No es posible defender un único criterio de valoración para la totalidad de las producciones del globo, ya que el potencial y alcance de cada práctica artística sólo puede ser evaluado en relación con su localización, con el particular escenario en el cual se propone intervenir. "La real calidad de una obra solamente puede ser percibida dentro de un conocimiento profundo del contexto al cual el objeto artístico fue destinado" (CAMNITZER, 1992. p. 71).

En conversación (02/06/2018) con el artista plástico venezolano José Luis Flores "Tachón", él sostiene que los espacios abiertos son una alternativa válida entre el creador y el público. Son los espacios privilegiados para la comunicación artística donde la comunidad se puede expresar porque la gran "obra" que producen artistas de las élites no representa la voz de los pueblos al proyectarse desde los espacios cerrados que generalmente son excluyentes.

El arte participativo en el espacio público y la creación colectiva para la transformación, señala que:

Las prácticas artísticas colectivas permiten poner en marcha la posibilidad de transformación de las propias realidades a través de poder imaginar colectivamente otros mundos posibles, y crearlos junto a otros en un primer ensayo ficcional del cambio potencial. Es un primer poner el cuerpo en la transformación, poner la imaginación en acto al encontrarse con otros, y de a poco comenzar a pensarse y sentirse colectivamente como sujeto activo de transformación de las propias realidades, creando una posibilidad de cambio y generando una confianza colectiva en esa posibilidad (BANG, 2013, p. 6).
Figura 3 - Detalle de obra Diablos Danzantes de Yare de Carlos Morgado

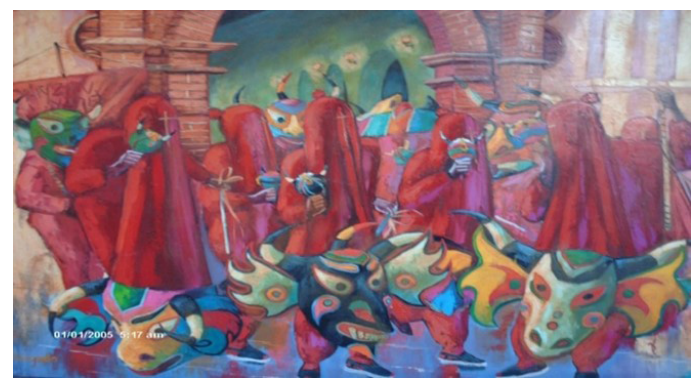

Foto: acervo ULAC

\section{Cómo fue que pasé del pincel a la escritura académica}

Aunque siempre me gustó escribir cosas sencillas de mi entorno familiar, el ambiente y las costumbres de mi pueblo, porque su importancia estaba en los detalles y expresiones de la gente, y tenían un gran sentido para mí, consideraba esta cualidad hasta ahora sólo para intelectuales o personas con una condición especial, porque ser escritor implica tener una gran imaginación creador, o al menos inclinación por nuestro entorno y acontecimientos o sucesos que nos circundan; confieso que el arte de escribir a mi parecer es una cualidad que no la tiene todo el mundo; lo que me llamó siempre la atención fue el arte de pintar, de expresarme libremente con la naturaleza, las expresiones de la gente, las montañas, ríos y sabanas como un sueño agradable, en el cual cuando uno se despierta se molesta consigo mismo.

Se podría decir que aprendemos a valorar el conocimiento, al compartir con el compañero, cada quien con su propia experiencia logro alcanzar el éxito al recibir algunas orientaciones de orden metodológico de 
investigación, allí es donde yo comienzo a producir escritos sobre mi trabajo de investigación, lo cual me dio algunas destrezas que ver mi interés para seguir avanzando en la conceptualización de un aprendizaje que ahora estoy narrando con el pincel, ya que cuando pinto un cuadro pareciera que también estoy escribiendo con los colores de mi espíritu puestos en mi paleta.

$\mathrm{Al}$ escribir en primera persona esta historia de vida, de mi largo transitar, están surgiendo nuevos elementos que la hacen más interesante, no sólo por los hechos y acontecimientos, producto del pasado, que son valorados por su contenido social, sino también al descubrir que poseo una especie de condición de escritor-historiador, que pinta la historia en colores para luego escribirla y más tarde exponerla, para que los actores sociales interpreten sobre este interesante episodio de mi vida, que creo apenas está comenzando a concretarse, en una audaz historia que empieza a dar buenos frutos.

De lo antes planteado, presento algunas escrituras que definen mi manera de narrar el significado de cada una de mis obras pictóricas, humanista, como por ejemplo, cuando me refiero a la obra denominada "Hoy no hubo que comer", desde su inicio me produjo una gran emoción, pues esta obra representaba la miseria humana, la necesidad, el hambre; en ella aparece una mujer y un hombre sentados alrededor de una mesa con un plato vacío, sus rostros hablan por sí solos, los invade una gran pena, se ven tristes, detrás de ellos una imagen de un santo Cristo dando señales de fe y esperanza, de tiempo mejores por venir, semántica visual que narra hechos y acontecimientos, que marcan precedentes socioculturales, políticos e históricos los cuales sostengo como teoría del arte social que despierta la sensibilidad y las emociones, al encuentro con la obra del artista.

Otra obra muy significativa fue la de "Los mendigos", en ella aparecen deambulando por las calles pidiendo un pedazo de pan. Actualmente, me pregunto qué me motivó a pintar estos cuadros de tanta tristeza, si no soy una persona triste; creo que lo que motivó podría ser mi espíritu de solidaridad $\mathrm{y}$ un tanto rebelde, por las injusticias que se cometen con los más vulnerables y despreciados por una sociedad desigual, que no les perdona el ser pobres, como si el ser pobres es un pecado. Desde allí, la lucha de clases de la que habla Carlos Marx (1850) de los niveles del concepto de clases sociales, la cual está relacionada directamente con la superación de una determinada formación social.

También pinté "La juramentación II", pienso que se desbordó el surrealismo, de acuerdo a lo expresado en la obra; allí aparecen diablos avanzando de rodillas en la entrada de la iglesia y en su parte interior, en lo más alto, un punto de luz por donde van saliendo, para llegar y alcanzar su purificación; a mano izquierda de la entrada está un ángel con sus brazos abiertos que trae en una mano la figura del Santo Patrón San Francisco de Paula, y en la otra las máscaras agarradas por el paño que las une en señal de retiro de esas almas que dieron o participaron siempre en la danza de Yare. En la imagen, el director de montaje, junto a Carlos Morgado. 
Figura 4 - Montaje de la exposición Diabladas Tradición en Resistencia, Museo Jacobo Borges; Caracas, 2014

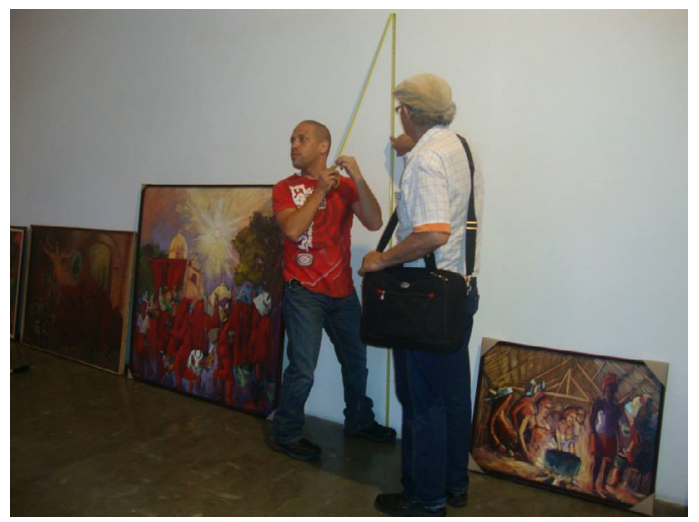

Foto: acervo ULAC.

De esta manera y sin tener ninguna duda, al dar inicio a mi autobiografía comprometida con mi historia de vida, al tratar de explicar mi propia vinculación desde el arte plástico, de involucrarme empíricamente con la investigación cualitativa, los cultores fueron cambiando mi manera de pensar y cuando me di cuenta, al tratar de expresar mi teoría basada en mis creencias, de sentidos y significados de este estudio autobiográfico, que he comenzado a observar que en sentido el hermenéutico existen dos mundos paralelos que visualizan y expresan las mismas características basadas en una realidad humana y conceptual.

De tal manera que, para poder asumir mi autobiografía narrativa surgió en mí una nueva manera de interpretar las cosas, las estrategias de indagación propias del método artístico y cultura visual conjuntamente con el método científico, en la aplicación de un nuevo instrumento, son producto del arte visual y subjetivo, que reconoce que si existen criterios que pueden ser aplicados desde la visión pictórica representados en los DDY.

Dentro de este marco, Blumer, en relación a la simbología y los significados, plantea lo siguiente:

El símbolo permite trascender el ámbito del estímulo... ampliar la percepción del entorno, incrementa la capacidad de resolución de problemas y facilita la imaginación y la fantasía". De igual manera afirma que "Los significados... son producto de la interacción social, principalmente la comunidad y comunicación que se convierte en esencia de cada sujeto [...]. El signo es el objeto material que desencadena el significado, y el significado el indicador social que interviene en la construcción de la conducta". Razones por las que "Las personas seleccionan, organizan, reproducen y transforman los significados en los procesos interpretativos en función de sus expectativas y propósitos (1986, p. 17).

En ese sentido, me considero un artista de expresión simbólica, ya que voy en busca de la belleza subjetiva e inmaterial que surge de las diferentes expresiones y elementos plásticos, para resolver una realidad conceptual que se expresa desde la caracterización de la manifestación de los DDY, desde la visión epistemológica y fenomenológica de tendencia hermenéutica crítica; basado en la búsqueda de nuevos valores de la espiritualidad religiosa a través del arte pictórico.

En este sentido, el estudio autobiográfico-narrativo que yo realizo para tratar de evidenciar la vinculación del pueblo de San Francisco de Yare en su expresividad cultural subjetiva, como proceso de transformación sociocultural y político, producido en los últimos cincuenta años, se refleja creativamente en la obra visual esperando la 
consolidación en síntesis pictórica, producto del esfuerzo por la manifestación de los DDY, como una de los alcances de mi tesis doctoral.

Y es a partir de esta autobiografía narrativa de mi vida como artista plástico - que busco contribuir en la construcción, validación y comprobación de aproximación teórica que permitan comprender y mejorar la gestión del Patrimonio Cultural, tanto a nivel local, como nacional y latinoamericano, desde una perspectiva orientada a la integración de este tipo de investigación en ciencias sociales, para entender mejor la complejidad de valorar el Patrimonio Cultural como identidad nacional, desde el reconocimiento de la obra plástica.

Figura 5 - Carlos Morgado en acción pictórica, Museo Jacobo Borges, 2014

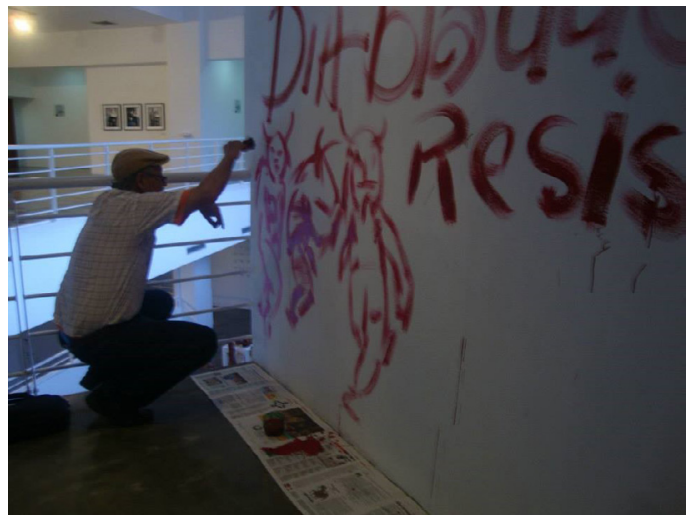

Foto: acervo ULAC.

\section{Conclusiones}

Esta conclusión relacionada entre el pincel creador y la historia del Corpus Christi en San Francisco de Yare, tiene su razón de ser al haber contribuido con mi experiencia al descubrimiento de una verdad real pictórica interpretada por todo un pueblo que la reconoce y la relaciona con los DDY. Donde los actores sociales la interpretan a través del dialogo y la trasmiten cada vez que llega la festividad del Corpus Christi, hecho que se ha producido durante medio siglo al irrumpir en estos espacios de la memoria colectiva que rompen paradigmas a campo abierto escenificando toda expresión de sensaciones y emociones del sincretismo, apartando un poco el arte individual para construir en colectivo una interacción social con artistas, pintores, músicos, poetas y escritores, fortaleciendo así el debate cultural y la comprensión en una realidad pictórica utilizando escenarios vivos mezclándose con la realidad del danzante al soltar toda su emoción frenética diablistica para luego ser interpretada en dos realidades con un mismo fin, vinculada a lo inmaterial de contenido sociocultural e histórico al producir impresiones y emociones a través de la expresión popular.

Por otra parte, en mis conclusiones se destacan los aspectos relevantes en relación a mi objeto de estudio por la interpretación que le dan los actores sociales a una realidad interpretada a través del lienzo trasmitiendo símbolos y significados en expresión inmaterial desde los hablan por la importancia que ha tenido el haber servido de aporte a la declaratoria de esta manifestación de Patrimonio Cultural Inmaterial de la Humanidad el día jueves 6 de diciembre de 2012 en Francia.

Este trabajo plantea que se puede seguir la historia de otras vidas, pero en $\mathrm{mi}$ caso ha sido diferente al volver a transitar por todo aquello caminos llenos virtudes y 
desaciertos que me llevaron a fortalecer mi condición de pintor como persona participante en una autobiografía-narrativa con la historia de mi vida que forma parte, de una $\mathrm{u}$ otra manera, del patrimonio cultural de América Latina.

\section{Resumo}

Este artigo aborda uma experiência plástica da minha vida diária ligada aos Diabos Dançantes de Yare (parte da festa de Corpus Christi, declarada património cultural imaterial da Humanidade pela Unesco em 12 de junho de 2012), a partir de visões, crenças e percepções presentes no meu trabalho pictórico, descobertas da experiência vivida da década de 1960 até o presente. Esta autobiografia foi localizada na cidade de São Francisco de Yare, grande palco ligado a estudos relacionados ao patrimônio imaterial. É importante lembrar que as complexidades formalizadas e a pesquisa orientada apresentadas são transformadas em identidades, expressas a partir do imaterial ao rito, mito, sincretismo, causando euforia e transmitindo emoções pela lona no espaço e na época de Corpus Christi na enunciação pictórica como autor. A teoria desenhada nesta pesquisa é orientada para a expansão de uma realidade pictórica sociocultural e histórica pouco abordada na Venezuela, emergindo da minha experiência como associado e ator social, identificar-me como parte desta manifestação mítico-religiosa.

Palavras-chave: Autobiografia. Corpus Christi. Patrimônio pictórico.

\section{Abstract}

This article is about a plastic experience from my daily life linked to the Dancing Devils of Yare (part of the feast of Corpus Christi declared Intangible Cultural Heritage of Humanity, by Unesco, on 12-12-2012). From my visions, beliefs and perceptions present in my pictorial work, findings from experience lived from the 1960s to the present. This autobiography was located in the town of San Francisco de Yare, large stage connected with studies related to intangible heritage. It is important to highlight that the formalized and research-oriented complexities, which I addressed here, are transformed into identities that are expressed from the immaterial with the rite, the myth, the syncretism, causing euphoria and emotions transmitted through the canvas in space and time of Corpus Christi in pictorial enunciation as author. The theoretical contribution that was intended to trace in this research is oriented towards the expansion of a sociocultural and historical pictorial reality little addressed in Venezuela, which emerges from my experience as a social actor and confrere, by identifying myself as part of this mythical-religious manifestation.

Keywords: Autobiography. Corpus Christi. Pictorial heritage. 


\section{Notas}

1 Objeto ritual de origen indígena, realizado de un solo palo hueco de alguna madera local y dentro le colocan semillas, tapando luego ambos extremos. El objeto es adornado, tallado generalmente con motivos vegetales. Su nombre se debe al sonido que produce al moverlo lentamente girando de arriba hacia abajo, el cual semeja el sonido de una fuerte lluvia cayendo, como se dice en lenguaje coloquial un "palo de agua".

2 Una etnia que se describe como devotos de la Virgen de Coromoto.

3 Relato del Capataz de los Diablos Danzantes de Yare, realizado el día 23 de febrero de 2015.

\section{Referencias}

BANG, C. El arte participativo en el espacio público y la creación colectiva para la transformación social. Experiencias actuales que potencian la creatividad comunitaria en la ciudad de Buenos Aires. Creatividad y sociedad, Buenos Aires, v. 20, p. 1-24, 2013. Disponible en: <http:/ / www.creatividadysociedad.com/ articulos / 20/2.\%20El\%20arte\%20participativo $\% 20$ en $\% 20 \mathrm{el} \% 20$ espacio $\% 20$ publico.pdf $>$. Consulta en: $1^{\circ}$ jun. 2018.

BLUMER, H. Symbolic interactionism: perspective and method. Berkeley: University of California Press, 1986.

CAMNITZER, L. Didáctica de la Liberación. Arte conceptualista latinoamericano. Murcia: Arts, 1992.

DUCCIO, D. Escribirse, la autobiografía como curación de uno mismo. Barcelona: Paidós, 1999.

HEIDEGGER, M. Hermenéutica-interpretativa. Barcelona: París, 2003.

RIGHETTI, Marco. Historias de vida, entre la literatura y la ciencia. Perfiles educativos, México, v. 28, n. 113, p. 81-105, enero 2006. Disponible en: <http://www.scielo. org. $\mathrm{mx} /$ scielo.php?script=sci_arttext\&pi$\mathrm{d}=$ S0185-26982006000300005\&lng=es\&nrm=iso>. Consulta en: 20 jul. 2018.
PALACIOS GARRIDO, A. Arte y contextos de acción en el espacio público. Creatividad y sociedad, (20), p. 1-24, 2013. Disponible en: <http:/ / www.creatividadysociedad.com/articulos $/ 17 / 6 \% 20$ arte $\% 20 y \% 20$ contextos $\% 20$ de\%20accion.pdf>. Consulta en: 20 jul 2018.

SOLÓRZANO, Gustavo. La Cofradía del Santísimo Sacramento del Altar de los Diablos Danzantes de Yare, perspectiva de comprensión desde sus actores sociales. 2017. Tesis (Doctorado en Patrimonio Cultural) - Universidad Latinoamericana y del Caribe Caracas-Venezuela, 2017.

UNESCO. Diablos danzantes de Venezuela. 2012. Disponible en: <https://ich.unesco.org/es/ RL/diablos-danzantes-de-venezuela-00639>. Consulta en: 25 abr. 2013. 